\title{
A Influência da Distribuição dos Juros sobre o Capital Próprio no Cálculo do Valor das Ações para Diferentes Investidores - O Caso das Entidades Fechadas de Previdência Complementar
}

\author{
Jaime Rogério Gomes Rangel \\ Mestre em Administração \\ Faculdades Ibmec RJ \\ Mestrado Profissionalizante em Administração \\ Av. Presidente Wilson, 118 sala 1117 - Centro \\ CEP 20030-020 - Rio de Janeiro - RJ - Brasil \\ jaimerog@previ.com.br \\ Raimundo Nonato Sousa da Silva \\ Professor Doutor \\ Faculdades Ibmec RJ \\ Mestrado Profissionalizante em Administração \\ Av. Presidente Wilson, 118 sala 1117 - Centro \\ CEP 20030-020 - Rio de Janeiro - RJ - Brasil \\ nonato@ibmecrj.br
}

\begin{abstract}
Resumo
A metodologia de avaliação de ações tem como princípio um conceito bastante simples - uma ação vale o valor presente dos fluxos de caixa futuros, descontados à uma taxa que represente o risco dessa ação. No entanto, tal modelo foi desenvolvido tendo como base os princípios contábeis americanos que, em alguns pontos, diferem daqueles utilizados na contabilidade brasileira. Um exemplo dessa diferença é que no Brasil, além dos dividendos, os acionistas podem participar dos lucros das companhias investidas por meio dos Juros Sobre o Capital Próprio - JSCP, que possui como principal vantagem a possibilidade de redução da carga tributária das companhias que utilizam tal instituto contábil, podendo gerar assim o aumento do valor das suas ações. No entanto, a influência da utilização do JSCP depende, dentre outros fatores, da natureza tributária dos investidores dessas companhias. Como forma de mensurar tal influência e utilizando o caso concreto da Tractebel Energia S/A o trabalho visa comparar o valor de suas ações caso fosse distribuído dividendos, JSCP para investidores pessoa física e JSCP para Entidades Fechadas de Previdência Complementar - EFPC, enfatizando a conclusão sob a ótica das EFPC por se tratar de investidor onde a geração de valor mostra-se relevante, além de serem importantes acionistas de empresas brasileiras.
\end{abstract}

Palavras-chave: Juros sobre o Capital Próprio, Avaliação de Ações, Entidade Fechada de Previdência Complementar

\begin{abstract}
One share is worth the present value of future cash flows discounted at a rate that reflects the share risk. As a consequence, every possibility that a company has to increase the generation of its cash flow can impact positively the value of its shares. In this sense, it's necessary to study the influence of Interests On Capital - IOC in the share value of Brazilian companies, because it's a way to distribute profits that has as a main advantage, comparing with usual dividends, the possibility of a tax reduction for the companies that use this accountancy instrument. However, the influence of the IOC depends on, amongst other factors, the tax
\end{abstract}


classification of the investors of those companies. The objective of this work is to measure such influence through the comparison of the share value of three Brazilian companies when decide to distribute profits through the payment of dividends, IOC for a personal shareholder and IOC for Pension Funds - PF. Another objective is, considering the greater influence for Pension Funds than for personal investors, and that some companies don't use the IOC, to alert the PF's asset managers that they have to make best efforts to avoid no distribution of IOC by invested companies, because, in some cases, these situation occur because these companies don't respect the best practices of corporate governance.

Key Words: Interest on capital, Assets evaluation, Complementary pension private entities.

\section{Introdução}

Um ativo vale os seus fluxos de caixa futuro gerados, descontados a valor presente pela taxa de risco deste ativo (ROSS, 1995, p. 101), desse modo, se o valor de uma empresa é função do seu fluxo de caixa gerado, à medida que exista alguma ação ou dispositivo, quer seja contábil ou financeiro, que reduza saídas de caixa ou aumente a geração de recursos líquidos, tal utilização poderá gerar valor para a empresa.

Partindo deste princípio e do fato de que o método de fluxo de caixa descontado tem como base os princípios contábeis americanos que, em alguns pontos, diferem daqueles utilizados na contabilidade brasileira, faz-se necessário analisar o fato de que a norma contábil vigente no Brasil desde 1996 prevê a possibilidade das empresas distribuírem resultados aos seus acionistas por intermédio da utilização dos Juros sobre o Capital Próprio - JSCP.

A JSCP é um dispositivo aprovado após a revogação da sistemática de correção monetária no início de 1996 com o objetivo de minorar os efeitos sobre os patrimônios das empresas, decorrentes da extinção da citada correção. O Artigo 10 da Lei 9.249 de 1995 regulamentada pelos Artigos 29 e 31 da Instrução Normativa 11/96 da Secretaria da Receita Federal - estabelece que, para efeito de apuração do lucro real, a partir de 01 de janeiro de 1996, observado o regime de competência, poderão ser deduzidos os juros pagos ou creditados individualmente a titular, sócio ou acionista, a título de remuneração do capital próprio, calculados sobre a conta do patrimônio líquido ajustado e limitado à variação pro rata die, da taxa de justos de longo prazo - TJLP, regulamentada por meio da resolução do Banco Central do Brasil número 2.121 de 30 de novembro de 1994.

Diferentemente dos dividendos, o JSCP é dedutível da base de cálculo do Imposto de Renda Pessoa Jurídica - IRPJ - e da Contribuição Social sobre o Lucro Líquido - CSLL, mediante a aplicação da Taxa de Juros de Longo Prazo sobre o montante do Patrimônio Líquido ajustado da empresa.

A empresa que utiliza tal dispositivo percebe economia de caixa de até $34 \%$ somatório das alíquotas de IRPJ e CSLL - do valor a ser distribuído aos seus acionistas a título de juros sobre o capital próprio, se comparado à hipótese de distribuição do mesmo montante por meio de dividendos.

Por outro lado, os acionistas não são tributados ao receberem dividendos, mas, dependendo da sua natureza tributária, serão tributados quando do recebimento do JSCP. Portanto, o que há que se analisar é o efeito líquido no fluxo de caixa do acionista quando da utilização deste instituto contábil, para que se perceba o seu real impacto no valor da sua participação na empresa.

A Lei $\mathrm{n}^{\circ}$. 9.249/95 prevê, como regra geral, que os investidores serão tributados no ato do recebimento do JSCP à taxa de $15 \%$ a título de Imposto de Renda. No entanto, algumas classes específicas de investidores, por possuírem diferentes naturezas tributárias, possuem diferentes bases de cálculo e alíquotas de recolhimento do referido imposto. 
Neste grupo encontram-se as Entidades Fechadas de Previdência Complementar EFPC, conforme preceitua a Lei no 11.053, de 29 de dezembro de 2004.

Tendo estas variáveis em foco, o objetivo deste trabalho é estudar até que ponto esta medida contábil, que é largamente utilizada pelas empresas brasileiras que são tributadas pelo Lucro Real, pode influenciar o valor das ações de uma companhia, de acordo com a natureza tributária dos seus investidores.

Para que esta influência possa ser medida, o trabalho buscará evidenciar a diferença existente no cálculo do valor da ação da Tractebel Energia S/A, considerando as mesmas premissas operacionais, financeiras e macroeconômicas, quando se é utilizado dividendo e quando se distribui JSCP, considerando acionistas pessoas físicas e EFPC.

Por fim, o trabalho visa concluir que, considerando a legislação brasileira, um mesmo ativo pode possuir diferentes valores, pois podem gerar diferentes fluxos de caixa para seus acionistas, adicionando assim uma perspectiva na avaliação de ações que geralmente circunscreve a sua análise ao ativo objeto, não se importando em pesquisar as particularidades do detentor da participação acionária.

\section{Avaliando Ações e o Valor da Empresa}

Com os estudos de Modigliani \& Miller - 1958 e 1963 - o valor de mercado da empresa passou a ser definido como o valor atual líquido do fluxo de rendimentos, adicionado do valor líquido dos benefícios fiscais do endividamento. A mensuração do valor da empresa tendo como base incentivos fiscais é uma tarefa que exige a superação de algumas dificuldades, entre elas, a complexidade da legislação fiscal e o problema de calcular alíquotas marginais de imposto de renda de pessoa jurídica. Graham (2000) apresenta uma função que relaciona a alíquota marginal efetiva de imposto de renda com o nível de endividamento, devido à expectativa de que, com alto endividamento, aumenta a probabilidade de a empresa não ter lucros tributáveis. O autor estima que, em média, o valor da empresa aumenta em 9,7\% se não for considerada a tributação da pessoa física e 4,3\% incluindo essa consideração, por causa do benefício fiscal.

Em função das características do trabalho e do objetivo a ser evidenciado - o impacto da utilização do JSCP no valor das ações de uma companhia -, será utilizada a abordagem do valor do patrimônio líquido, o qual é obtido descontando-se os fluxos de caixa esperados pelo acionista, ou seja, os fluxos de caixa residuais após a dedução de todas as despesas, bônus fiscais, pagamentos de juros e principal, ao custo de patrimônio líquido, isto é, a taxa de retorno exigida pelos investidores sobre o patrimônio líquido da empresa.

Segundo Damodaran (1997, p. 12) existem dois caminhos para a avaliação por fluxo de caixa descontado: o primeiro é avaliar apenas a participação acionária no negócio, enquanto o segundo é avaliar a empresa como um todo, que inclui, além da participação acionária, a participação dos demais detentores de direitos na empresa (detentores de bônus, debêntures, etc).

Embora ambas as abordagens descontem fluxos de caixa esperados, os fluxos de caixa e taxas de desconto são diferentes em cada caminho, no entanto, as suas abordagens produzirão estimativas consistentes de valor, desde que o mesmo conjunto de pressuposições seja utilizado em ambas.

Para Damodaran (1997, p. 123), investidores num ativo recebem um direito residual sobre seus fluxos de caixa, isto é, têm direito a quaisquer fluxos de caixa excedentes após o atendimento de todas as obrigações financeiras, incluindo o pagamento das dívidas e depois que tenham sido atendidas as necessidades de reinvestimento da empresa.

O fluxo de caixa do acionista é, portanto, o fluxo de caixa existente após o pagamento de despesas operacionais, juros e de principal, e de qualquer desembolso de capital necessário à manutenção da taxa de crescimento dos fluxos de caixa projetados. 
O FCLA pode ser medido da seguinte forma:

FCLA $=$ Lucro Líquido + Depreciação - Desembolsos de Capital $-\Delta$ Necessidade de Capital de Giro - Amortização de Dívida + Novas Emissões de Dívida

Como conseqüência utilizaremos o seguinte modelo de precificação das ações:

$$
\underset{\substack{\mathrm{t}=\mathrm{n} 1 \\ \mathrm{t}=1}}{\mathrm{t}=\mathrm{n} 2} \mathrm{PCLA}_{t} /(1+\mathrm{r})^{t}+\underset{\sum}{\mathrm{FCLA}_{t} /(1+\mathrm{r})^{t}+\ldots \ldots \ldots+\mathrm{P}_{\mathrm{n} 2} /(1+\mathrm{r})^{n}}
$$

Onde $\mathrm{P}_{0}=$ valor atual da ação

$\mathrm{FCLA}_{t}=$ FCLA no ano $\mathrm{t}$

$\mathrm{P}_{\mathrm{n} 2}=$ preço final ao término do período de transição $=$ FCLA $_{\mathrm{n} 2+1} /(\mathrm{r}-$

$\left.\mathrm{g}_{\mathrm{n}}\right)$

$\mathrm{r}=$ custo do patrimônio líquido

$\mathrm{n} 1$ = final do período 1

$\mathrm{n} 2=$ final do período 2

Relativamente ao custo do patrimônio Líquido - r, Copeland (2001, p. 236) recomenda o uso do modelo Capital Asset Pricing Model - CAPM ou o modelo de precificação por arbitragem - APT para estimar o custo de oportunidade do capital acionário.

Considerando que ambos possuem limitações, o estudo tem por base a utilização do modelo CAPM devido à sua maior utilização prática em estudos de mesma natureza. Em essência, o CAPM postula que o custo de oportunidade do capital é igual ao retorno dos títulos livre de risco mais o risco sistemático da empresa (beta), multiplicado pelo prêmio de risco de mercado.

O CAPM mede o risco em termos de variância não-diversificável e relaciona os retornos esperados a esta medida de risco. O risco não-diversificável para qualquer ativo é medido pelo seu beta, que pode ser utilizado para gerar um retorno esperado.

$$
\mathrm{E}(\mathrm{R})=\mathrm{Rf}+\text { Beta do Patrimônio Líquido }(\mathrm{E}[\mathrm{Rm}]-\mathrm{Rf})
$$

Onde $\mathrm{Rf}=$ taxa livre de risco

$\mathrm{E}(\mathrm{Rm})=$ retorno esperado sobre o índice de mercado

O retorno que os investidores esperam ganhar sobre um investimento patrimonial, dado o risco a ele inerente, se torna o custo do patrimônio líquido para os gerentes da empresa.

São necessários os seguintes dados de entrada para a utilização do CAPM: a taxa livre de risco em vigor, o retorno esperado sobre o índice de mercado e o beta do ativo objeto de análise.

As premissas relativas às projeções tanto do fluxo de caixa líquido da companhia quanto do custo do patrimônio líquido serão utilizadas no trabalho tendo por base o cenário atual e esperado para o mercado acionário brasileiro, para os indicadores macroeconômicos, bem como considerará as características particulares da empresa em questão.

\section{Juros Sobre o Capital Próprio}




\subsection{Uma Visão Histórica da Utilização do JSCP Como Uma Evolução dos Sistemas de Contabilização do Custo de Oportunidade}

Martins (2001, p.186) afirma que os agentes econômicos que possuem recursos disponíveis deparam com várias possibilidades de investimento, as quais possuem como características principais a remuneração, o prazo e o risco.

À medida que selecionamos uma das alternativas de investimento existentes, é possível que percamos os benefícios das demais. Então, a melhor escolha consubstancia-se na que maximiza a satisfação do agente.

Nascimento (1998, p. 28) assim descreve a essência do custo de oportunidade:

"Na empresa, toda vez que existirem problemas de escolha entre as várias alternativas da ação, estará presente o conceito de custo de oportunidade. Quando analisa várias alternativas de decisão, o decisor, intuitiva ou propositadamente, sempre se perguntará se o benefício a ser obtido, em relação ao sacrifício de recursos correspondentes, será o melhor possível nas circunstâncias em que a decisão está sendo tomada. Essa é a exata essência do conceito de custo de oportunidade."

Nessa ótica, a comparação entre o investimento aceito e a melhor alternativa rejeitada pode oferecer relevantes elementos para avaliar a decisão. Caso o primeiro supere a segunda, a escolha foi acertada e registramos um lucro. Se ocorrer o contrário, apuramos um prejuízo e evidenciamos que a ação não maximizou (realizada) ou maximizará (planejada) os benefícios possíveis.

O conceito de custo de oportunidade tem utilizado duas abordagens, quais sejam, a abordagem econômica e a abordagem contábil.

\subsubsection{Abordagem Econômica}

As organizações demandam, junto ao meio ambiente, gama variada de recursos. Estes são processados, transformados em bens e serviços e desenvolvidos à sociedade, visando satisfazer a suas necessidades.

Dessa forma, as empresas estão num contexto de recursos escassos, para atender às necessidades ilimitadas. Portanto as possibilidades de uso alternativo desses recursos fazem com que passemos de um problema tecnológico, no qual se busca a melhor combinação dos fatores de produção, para um problema econômico.

Para Friedman (1971, p. 9), "um problema econômico existe, sempre que meios escassos sejam usados para satisfazer a fins alternativos". Verificamos, então, um valor econômico para esses bens, cujas condições básicas para sua ocorrência, no entender de Mill (1943, p. 448), são as seguintes:

1. possuir utilidade capaz de satisfazer a alguma necessidade humana; e

2. apresentar alguma dificuldade para sua obtenção.

Considerando que a obtenção de algo geralmente envolve um sacrifício, este se constitui no custo, cuja expressão monetária é dada pelo preço transacionado no mercado.

Na discussão sobre custos, Watson e Holman (1979, p. 147 e 148) afirmam que: "O conceito fundamental do custo alternativo, ou seja, o custo de qualquer coisa é o valor da melhor alternativa, ou a oportunidade, que é sacrificada.".

Acreditamos que a exemplificação efetuada por Martins (1996a, p. 433) arremata o entendimento genérico do conceito. É a seguinte: 
"Custo de Oportunidade significa o quanto alguém deixou de ganhar por ter adotado uma alternativa em vez de outra, ou seja, se alguém escolheu investir em uma fábrica de giz, deixando de, com isso, investir na construção de um supermercado, que era a segunda melhor alternativa existente na época, diz-se que o Custo de Oportunidade da decisão de investir na fábrica de giz é o quanto se deixou de ganhar por não construir o supermercado.

Assim, o lucro 'econômico' da decisão pelo investimento na fábrica é o quanto ela produzir de resultado depois de se deduzir dele o lucro que teria sido obtido pelo investimento no supermercado (...)

Esse conceito é válido não só para decisões econômicas mas para as decisões de qualquer natureza de toda pessoa. $O$ custo de oportunidade do leitor ao decidir ler essa matéria é o que ele deixou de fazer durante esse tempo. $O$ custo de Oportunidade de se ir ao jogo de futebol é o churrasco perdido que ocorreu ao mesmo tempo. $\mathrm{E}$ assim por diante."

\subsubsection{Abordagem Contábil}

Ainda segundo Martins (2001, p.189) a literatura contábil tem dado bastante atenção ao custo de oportunidade. Destacamos as questões que envolvem sua aplicabilidade na gestão empresarial, explorando o enfoque pragmático da área.

"Este é um conceito costumeiramente chamado de 'econômico' e 'não contábil', o que em si explica, mas não justifica, o seu não muito uso em Contabilidade Geral ou de Custos."

Portanto, o custo de oportunidade pode ser empregado em relatórios destinados aos usuários internos e externos. No entanto, é nos textos sobre contabilidade gerencial e administração financeira que encontramos freqüentes referências sobre esse conceito.

Nascimento (1998, p. 131) afirma:

"Na literatura, existem vários modelos para o cálculo e contabilização dos custos de oportunidade. Nem todos aplicam o conceito, diretamente, a cada decisão tomada na empresa, e sim, a um conjunto de decisões. Um dos caminhos preferidos para a aplicação do conceito é o reconhecimento dos juros sobre o capital, empregado nas operações.

Existem, entretanto, modelos nos quais o conceito é aplicado a cada decisão, e em conjunto com a aplicação do conceito de juros sobre o capital próprio. Independentemente das vantagens dos modelos mais completos, em termos da qualidade da informação que proporcionam ambos os tipos têm o mérito de, no mínimo, deslocarem as discussões para o nível da praticidade."

\subsection{Substituto das Técnicas de Correção Monetária}

Segundo Martins (1996a, p. 431), no Brasil, um dos usos pragmáticos para os juros sobre o capital próprio consiste em funcionar como um substituto das técnicas de correção monetária das demonstrações contábeis. 
A história brasileira recente de combate à inflação parece ter demonstrado que os esforços técnicos da economia são insuficientes para essa tarefa. Só com o apoio da psicologia social e do marketing foi possível alcançar uma percepção majoritária de que a perda do poder aquisitivo poder da moeda havia sido controlada.

Esse contexto tornou o pronunciamento da expressão correção monetária um pecado capital. Foi implementado, então, um dispositivo contábil, para reconhecer, mesmo que parcialmente, os efeitos da inflação existente. Seu resultado foi a promulgação da Lei 9.249/95, que estabeleceu a faculdade da adoção dos juros sobre o capital próprio para as empresas brasileiras.

Ainda conforme Martins (1996a, p. 429 e 430), num contexto de baixa inflação, essa substituição seria válida, porque:

"a longo prazo,o relevante não é corrigir ou não corrigir estoques, corrigir ou não corrigir Imobilizado e outros Ativos, já que estes são aumentados pela atualização mas depois descarregados para a despesa pelo valor corrigido, anulando-se o efeito do tempo; o relevante é corrigir o Patrimônio Líquido, para que o lucro seja, no tempo, exatamente a diferença entre os valores colocados e retirados pelos sócios. Afinal, lucro é o que faz crescer, em termos reais, o Patrimônio Líquido da empresa".

Portanto, se aplicássemos uma taxa de juros idêntica à inflação existente sobre o capital próprio (patrimônio líquido), estaríamos corrigindo monetariamente os relatórios contábeis de uma forma simplificada.

A Lei $n^{0} .9 .249 / 95$ introduziu diversas modificações na legislação societária e fiscal que passaram a influenciar a gestão corporativa no Brasil. A alteração que está mais intimamente ligada ao tema deste trabalho foi a remuneração do capital próprio, conforme art. $9^{\circ}$ daquele diploma legal, o qual descrevemos já com as modificações feitas por intermédio da Lei no. 9.430, de 27/12/96.

“Art. $9^{0}$ A pessoa jurídica poderá deduzir, para efeitos da apuração do lucro real, os juros pagos ou creditados individualizadamente a titular, sócios ou acionistas, a título de remuneração do capital próprio, calculados sobre as contas do patrimônio líquido e limitados à variação, pro rata dia, da Taxa de Juros de Longo Prazo-TJLP".

Parágrafo $1^{\circ}$. O efetivo pagamento ou crédito de juros fica condicionado à existência de lucros, computados antes da dedução dos juros, ou de lucros acumulados e reservas de lucros, em montante igual ou superior ao valor de duas vezes os juros a serem pagos ou creditados.

Parágrafo $2^{\circ}$. Os juros ficarão sujeitos à incidência do imposto de renda na fonte à alíquota de quinze por cento, na data do pagamento ou crédito ao beneficiário."

Parágrafo $3^{\circ}$. O imposto retido na fonte será considerado:

I - antecipação do devido na declaração de rendimentos, no caso de beneficiários pessoas jurídicas tributadas com base no lucro real, presumido ou arbitrado; II - tributação definitiva, no caso de beneficiário pessoa física ou pessoa jurídica isenta." 
A maior vantagem financeira propiciada a partir de 1997, entretanto, foi a revogação do parágrafo 10 do art. $9^{\circ}$. da Lei 9.249/95. Tal norma dispunha que os juros sobre o capital próprio eram indedutíveis na determinação da base de cálculo da Contribuição Social sobre o Lucro Líquido - CSLL. Com a revogação do referido parágrafo, a partir de 01/01/97 os juros calculados sobre o capital próprio passaram a ser dedutíveis tanto na determinação do lucro real como da base de cálculo da CSLL.

O uso dos juros sobre o patrimônio líquido não é obrigatório. Faz parte das opções disponíveis ao gestor financeiro da empresa para remunerar o acionista quando a empresa é tributada pelo lucro real.

A partir de 1996, o conceito de remuneração do capital próprio através de juros ficou inserido na legislação nacional não apenas em situações particulares, como as constantes na legislação de períodos anteriores, mas em caráter um pouco mais ampliado.

A dedutibilidade fiscal dos juros sobre o capital próprio na determinação do lucro real e da base de cálculo da CSLL está limitada ao maior dos seguintes valores:

1. $50 \%$ do lucro líquido do período de apuração após a dedução da CSLL (valor provisório, antes de computar o efeito dos juros sobre o capital próprio na sua base de cálculo) e antes da dedução dos juros sobre o capital próprio e da provisão para o IRPJ (art.29, Inc. I e Parágrafo Único, da IN SRF n ${ }^{\circ}$. 93/97); ou

2. 50\% do somatório dos lucros acumulados e reservas de lucros de períodos de apuração anteriores (art. 29, Inc. II, da IN SRF $n^{\circ} .93 / 97$; art. 30, parágrafo $3^{\circ}$, alínea b, da IN SRF $n^{\circ}$. 11/96).

\subsection{Juros Remuneratórios Sobre o Capital Próprio em Outros Países.}

Rolim (1996a, p.110; 1996b, p. 235) informa que não foi possível encontrar, através do Direito Comparado, remuneração idêntica à do art. $9^{\circ}$ da Lei $\mathrm{n}^{\circ}$ 9.249/95 em outros países.

Martins (1996b, p. 438), narra que a figura dos juros remuneratórios do capital próprio é antiga em termos acadêmicos e conceituais, mas "mundialmente é novidade para empresas em operação".

Segundo ainda Martins (1996a, p. 431), "seria a primeira vez, que se saiba, que se introduziria, no mundo, a figura do Juro Sobre o Capital Próprio nas empresas em operação".

De acordo com Girardi e Boschi (2000), os juros sobre o capital próprio na forma prevista na Lei $n^{\circ}$. 9.249/95 foram uma inovação brasileira.

No entanto, é necessário lembrar que trabalhos propugnando o registro de um custo de oportunidade do capital próprio existem há muito tempo e que, geralmente, foram e são muito usados em diversas empresas e países. Basta lembrar que os custos calculatórios (sic para a tradução) da contabilidade gerencial germânica são antiquíssimos. Haja vista o método de custeio conhecido por RKW que, muito antes do ABC (Activity Based Costing ou Custeio Baseado em Atividades), já alocava todos os custos e despesas aos produtos, inclusive os juros sobre o capital próprio.

\subsection{Natureza Tributária das Entidades Fechadas de Previdência Complementar - EFPC}

A Lei no 11.053, de 29 de dezembro de 2004 dispõe sobre a tributação dos planos de benefícios de caráter previdenciário, cujo seu artigo $5^{\circ}$ prevê:

"A partir de $1^{0}$ de janeiro de 2005 , ficam dispensados a retenção na fonte e o pagamento em separado do imposto de renda sobre os rendimentos e ganhos auferidos nas aplicações de recursos das provisões, reservas técnicas e fundos de planos de benefícios de entidade de previdência complementar, sociedade seguradora e FAPI, bem como de seguro de vida com cláusula de cobertura por sobrevivência."

A Influência da Distribuição dos Juros sobre o Capital Próprio... 
Como conseqüência, a legislação concede caráter tributário privilegiado as EFPC, fazendo com que não tenham que recolher o imposto de renda na fonte de $15 \%$, quando da distribuição do JSCP por parte das empresas participadas, promovendo assim uma vantagem adicional se comparada aos investidores pessoa física, uma vez que não dispõem do referido benefício.

\section{A Aplicação do Caso Prático - Tractebel Energia S/A}

Nesta parte do trabalho, usaremos os conceitos já dispostos anteriormente - cálculo do valor de uma ação pelo modelo de desconto de fluxo de caixa livre para o acionista ao custo do capital próprio - CAPM, com intuito de perceber qual a diferença na precificação de uma ação à medida que se utiliza a remuneração aos investidores por meio de dividendos e por intermédio da distribuição de JSCP.

Neste exemplo prático, utilizaremos a projeção das ações da Tractebel Energia S/A que, embora já tenha distribuído aos seus acionistas JSCP em anos anteriores, no exercício encerrado em 31/12/2004 optou pela distribuição de dividendos.

Por si só uma investigação acerca dos motivos pelos quais algumas empresas deixam de utilizar esta forma de planejamento tributário já seria matéria para uma análise bastante abrangente, no entanto, não faz parte do escopo deste trabalho em função da extensão que a obra tomaria.

Para alcançar o objetivo do trabalho, o processo inicia-se com a projeção dos resultados da companhia, logo após do fluxo de caixa livre da empresa e, por último, o fluxo de caixa dos acionistas.

A expectativa é que a empresa tenha sua vida útil por prazo indeterminado e serão feitos exercícios considerando a distribuição de dividendos, bem como o cálculo do valor da ação considerando o JSCP considerando o seu pagamento a um acionista pessoa física e também à EFPC.

Conforme cita a Lei 9.249/95, a regra geral estabelece que o acionista no ato do recebimento do JSCP seja tributado em $15 \%$ do valor a receber a título de IRRF. Portanto, a diferença a ser apurada nos exercícios de valor de ação utilizando o JSCP para pessoa física e EFPC é exclusivamente a incidência desta dedução no valor a receber por parte dos acionistas pessoas físicas.

Dada a sua complexidade, este estudo não pretende exaurir todas as dimensões que um exercício de projeção de fluxo de caixa permite na fundamentação das premissas operacionais, financeiras e macroeconômicas da Tractebel, mas sim demonstrar que, utilizando as mesmas premissas nos três cenários a serem estudados, o valor das ações da companhia a ser apurado difere quando se é utilizado o JSCP e em função da natureza contábil dos investidores em análise.

Outro aspecto a ser ressaltado é que este estudo também não objetiva precificar todas as particularidades do sistema contábil brasileiro vigente na atualidade que possam diferir do padrão contábil americano.

Além disso, o modelo utilizará como premissas:

1. Projeção de vendas e despesas num horizonte temporal de 9 anos, ou seja, parte da base do balanço encerrado em 31/12/2004 e projeta o período compreendido entre os anos de 2005 a 2013, com perpetuidade a partir do ano 10.

2. Taxa de crescimento na perpetuidade conforme projeção do PIB, coletado como média de consultorias que operam no mercado brasileiro.

3. A projeção é feita em termos nominais.

4. O beta utilizado foi coletado junto ao sistema Economática. 
5. As premissas macroeconômicas terão por base as médias de consultorias que atuam no mercado brasileiro.

6. O somatório das alíquotas de IRPJ e CSLL alcança $34 \%$.

\subsection{Resultados do Exercício I - Valor da Ação Apurado por Meio da Distribuição de} Dividendos

\begin{tabular}{|c|c|c|}
\hline AVALIAÇ̃̃O & & \\
\hline Valor presente líquido do fluxo do acionista por 1000 ações & $\$$ & 6.3305 \\
\hline Valor presente líquido da perpetuidade por 1000 ações & $\$$ & 5.7941 \\
\hline Caixa por 1000 ações & $\$$ & 0.0118 \\
\hline Investimentos por 1000 ações & $\$$ & 0.0772 \\
\hline VALOR PARA O ACIONISTA & $\$$ & 12.2136 \\
\hline
\end{tabular}

\subsection{Resultados do Exercício II - Valor da Ação Encontrado pela Utilização do JSCP com Investidores Pessoa Física}

\begin{tabular}{lrr}
\hline \multicolumn{2}{c}{ AVALIAÇ̃̃ } & \\
Valor presente líquido do fluxo do acionista por 1000 ações & $\$$ & 6.7162 \\
Valor presente líquido da perpetuidade por 1000 ações & $\$$ & 5.9736 \\
Caixa por 1000 ações & $\$$ & 0.0118 \\
Investimentos por 1000 ações & $\$$ & 0.0772 \\
& VALOR PARA O ACIONISTA & $\mathbf{1 2 . 7 7 8 7}$
\end{tabular}

4.3. Resultados do Exercício III - Valor da Ação Encontrado pela Utilização JSCP Pagos a Investidores Entidades Fechadas de Previdência Complementar

\begin{tabular}{lrr}
\hline \multicolumn{1}{c}{ AVALIACC̃̃O } & \\
Valor presente líquido do fluxo do acionista por 1000 ações & $\$$ & 7.0207 \\
Valor presente líquido da perpetuidade por 1000 ações & $\$$ & 6.1152 \\
Caixa por 1000 ações & $\$$ & 0.0118 \\
Investimentos por 1000 ações & $\$$ & 0.0772 \\
& VALOR PARA O ACIONISTA & $\mathbf{1 3 . 2 2 4 9}$
\end{tabular}

\section{Conclusões}

O quadro comparativo abaixo demonstra a comparação dos valores apurados para as ações da empresa nos três cenários propostos: 


\begin{tabular}{|rr|r|rr|}
\hline $\begin{array}{r}\text { EXERCÍCIO } \\
\text { DIVIDENDO }\end{array}$ & \multicolumn{2}{|c|}{ EXERCÍCIO } & \multicolumn{2}{|c|}{ EXERCÍCIO } \\
\hline JSCP - PF & \multicolumn{2}{|c|}{ JSCP - EFPC } \\
\hline $\mathrm{R} \$ 12,21$ & $\mathrm{R} \$$ & 12,78 & $\mathrm{R} \$$ & 13,22 \\
\hline
\end{tabular}

Tendo como base o valor apurado por meio da distribuição do JSCP para EFPC, podemos notar a diferença em termos percentuais dos valores encontrados para as ações da Tractebel:

\begin{tabular}{|r|c|c|}
\hline EXERCÍCIO & EXERCÍCIO & EXERCÍCIO \\
DIVIDENDOS & $\begin{array}{c}\text { JSCP - PF } \\
\text { JSCP - EFPC }\end{array}$ \\
\hline $8,28 \%$ & $3,49 \%$ & - \\
\hline
\end{tabular}

No exercício efetuado, o resultado evidencia que quando é utilizado JSCP, considerando a tributação de pessoa física - 15\% - o valor da ação é superior em aproximadamente $3,49 \%$ ao valor que seria apurado pelo acionista caso fosse distribuído dividendos. Já no caso onde o investidor considerado foi EFPC, o valor apurado para a ação foi $8,28 \%$ superior àquele calculado por intermédio dos dividendos.

Este resultado confirma na prática a idéia inicial de que, quando utilizado o JSCP, o valor das ações da empresa tendem a se valorizar pois há uma economia de caixa relativa ao não pagamento de parcela dos tributos.

A pequena diferença encontrada nos valores relativos à distribuição de JSCP ao investidor pessoa física e EFPC deriva do fato de que o fluxo de caixa líquido gerado pela companhia é bastante superior aos valores distribuídos a título de JSCP.

Tal situação mostra-se relevante, pois foi utilizada a premissa de que o excesso de caixa gerado pela companhia, além do JSCP, também sensibiliza o fluxo de caixa dos acionistas, uma vez que a estes pertencem, embora não distribuído naquele momento por diversos motivos, dentre os quais, a expectativa de geração de retornos futuros superiores ao custo de oportunidade.

Os exercícios demonstraram situação potencial de valor das ações da companhia caso continue a distribuir dividendos ou na hipótese em que volte a distribuir JSCP.

Outro ponto a ser considerado é que, tal melhora na avaliação das ações, torna-se mais relevante no caso onde o investidor seja EFPC.

Uma conclusão inicial que se pode fazer do resultado do trabalho é que a utilização não muito criteriosa dos conceitos básicos de avaliação de ações sem os devidos ajustes à realidade contábil e normativa brasileira pode resultar num desvio relevante em relação aos preços dos ativos, dependendo do contexto onde é utilizada.

Essa diferença por vezes pode ser suficiente para se decidir pela não realização de um negócio que pode ser vantajoso, se olhado com os devidos cuidados, ou até mesmo pode-se concluir por fazê-lo sem mensurar os possíveis impactos financeiros que ocorrerão no momento da implementação do plano de negócios que irá buscar o retorno almejado.

Outro aspecto a ser considerado é que se o valor de uma ação depende de fatores relacionados a quem a compra, significa que essa dimensão de alguma forma deve ser estudada para que simplificações em excesso não prejudiquem o resultado final a ser alcançado.

Os resultados do trabalho permitem concluir que, em função da sua natureza tributária, as EFPC brasileiras possuem um desafio adicional na gestão de suas participações, qual seja, devem ser envidados esforços para que as empresas participadas avaliem cuidadosamente as motivações pela não utilização do JSCP, pois pode gerar prejuízos para essa classe de investidores relevantes de longo prazo no mercado acionário brasileiro. 
Tal situação acentua-se à medida que as EFPC alcancem sua fase de maturidade, onde faz-se ainda mais premente a maximização dos proventos advindos das companhias participadas.

Embora não seja foco do estudo, uma análise mais aprofundada das motivações pelas quais algumas empresas não utilizam tal dispositivo contábil pode sugerir problemas que se aproximam das situações de conflito de interesses, pois em muitos casos esta forma de planejamento tributário não é utilizada em função de características inerentes exclusivamente ao controlador das companhias, como por exemplo, tributação do JSCP no país de origem, sede da companhia em paraísos fiscais, fazendo com que a empresa pague mais impostos e conseqüentemente provocando perdas a outras classes de acionistas com natureza tributáira distinta.

\section{Referências Bibliográficas}

BRASIL. Lei no 9.249, de 26 de dezembro de 1995. Altera a legislação do imposto de renda das pessoas jurídicas, bem como da contribuição social sobre o lucro líquido. Diário Oficial [da] República Federativa do Brasil, Brasília, p.22301-22304, 27 dez. 1995.

Lei $\mathrm{n}^{\circ}$ 9.430, de 27 de dezembro de 1996. Dispõe sobre a legislação tributária federal, as contribuições para a seguridade social, o processo administrativo de consulta. Diário Oficial [da] República Federativa do Brasil, Brasília, p.28805-28814, 30 dez. 1996.

Lei no 11.053, DE 29 de dezembro de 2004. Dispõe sobre a tributação dos planos de benefícios de caráter previdenciário e dá outras providências. Diário Oficial [da] República Federativa do Brasil, Brasília, 30 dez. 2004.

ano calendário de 1996. Diário Oficial [da] República Federativa do Brasil, Brasília, p.2856-2865, 22 fev. 1996.

Instrução Normativa SRF no 93, de 24 de dezembro de 1997. Dispõe sobre a apuração do imposto de renda e da contribuição social sobre o lucro das pessoas jurídicas a partir do ano-calendário de 1997. Diário Oficial [da] República Federativa do Brasil, Brasília, p.31519-31525, 29 dez. 1997.

COPELAND, Tomas E. Avaliação de ações - Valuation. São Paulo: MAKRON Books, 2000.

DAMODARAN, Aswath. Avaliação de investimentos: ferramentas e técnicas para a determinação do valor de qualquer ativo. Rio de Janeiro: Qualitymark, 1997.

FRIEDMAN, Milton. Teoria dos preços. Rio de Janeiro: Apec,1971.

GRAHAM, John R. How big are the tax benefits of debt?. The Journal of Finance, V.55, n.5, p.1901-1941.oct.2000

GIRARDI, Alexandre; BOSCHI, Álvaro Luiz. Teorias de política de dividendos versos juros sobre capital próprio: um estudo nas indústrias têxteis da Região Sul. In: CONGRESSO

BRASILEIRO DE CONTABILIDADE, 16, 2000, Goiânia. Anais eletrônicos... [on line]. Disponível em: <http://www.iceg.pucminas.br/contabeis/16cbc/cbc/docs/tema8.htm>. Acesso em: 4 maio 2001.

MARTINS, Eliseu. Avaliação de Empresas: da mensuração contábil à econômica / FIPECAFI; Eliseu Martins (organizador). - São Paulo: Atlas, 2001.

. Extinção da correção monetária: os juros sobre o capital próprio (TJLP) e os dividendos (1 ${ }^{\mathrm{a}}$. parte). IOB - São Paulo, Boletim n.43/96, 1996a. Temática Contábil, p. 433 426.

Extinção da correção monetária: os juros sobre o capital próprio (TJLP) e os dividendos ( $2^{\mathrm{a}}$. parte). IOB - São Paulo, Boletim n.44/96, 1996b. Temática Contábil e p. 446437. 
NASCIMENTO, Auster Moreira. Uma contribuição para o estudo dos custos de oportunidade. Dissertação (Mestrado em Contabilidade) - Faculdade de Economia, Administração e Contabilidade. São Paulo: Universidade de São Paulo, 1998.

NESS, Walter Lee e ZANI, João. Os juros sobre capital próprio versus a vantagem do endividamento. RAUSP, Vol. 36, numero 2, p. 89-102, m2001, São Paulo. .

PROCIANOY, Jairo e POLI, Beatriz T. C. A resposta das empresas à modificação tributária de 1990: dividendos e ganhos de capital. Anais do Enanpad 1994, 18 vols., 1994, p. 200212.

ROLIM, João Dácio. Remuneração do capital próprio das pessoas jurídicas - aspectos fiscais. In: ROCHA, Valdir de Oliveira (coord.). Imposto de renda: alterações fundamentais. São Paulo: Dialética, 1996a. p.107-23.

ROSS, Stephen A.; WESTERFIELD, Randolph W. Administração financeira. São Paulo: Atlas, 1995.

WATSON, Donald S., HOLMAN, Mary A. Microeconomia. São Paulo: Saraiva, 1979. 